\title{
Irradiation Assisted Stress Corrosion Cracking Susceptibility of Alloy X-750 exposed to BWR environments
}

S. Teysseyre, J.H. Jackson, P.L. Andresen, P. Chou, B. Carter

October 2017

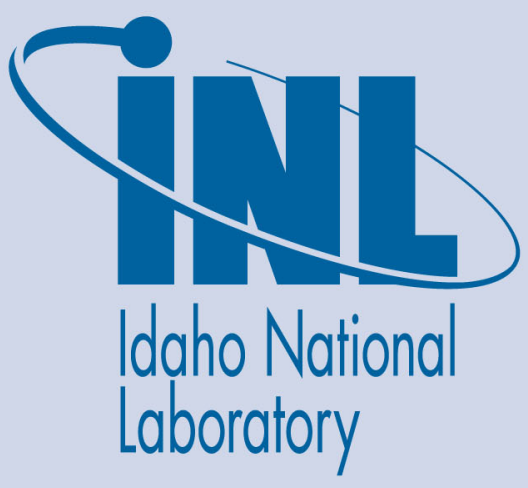

The INL is a U.S. Department of Energy National Laboratory operated by Battelle Energy Alliance 


\section{Irradiation Assisted Stress Corrosion Cracking Susceptibility of Alloy X-750 exposed to BWR environments}

S. Teysseyre, J.H. Jackson, P.L. Andresen, P. Chou, B. Carter

October 2017

Idaho National Laboratory Idaho Falls, Idaho 83415

http://www.inl.gov

Prepared for the

U.S. Department of Energy

Under DOE Idaho Operations Office

Contract DE-AC07-05ID14517 


\title{
Irradiation Assisted Stress Corrosion Cracking Susceptibility of Alloy X-750 exposed to BWR environments
}

\author{
S. Teysseyre ${ }^{1}$, J.H. Jackson ${ }^{1}$, P. L. Andresen ${ }^{2}$, P. $\mathrm{Chou}^{3}$, B. Carter ${ }^{3}$ \\ ${ }^{1}$ Idaho National Laboratory \\ ${ }^{2}$ GE Global Research Center \\ ${ }^{3}$ Electric Power Research Institute
}

\begin{abstract}
The effect of irradiation on stress corrosion cracking susceptibility and fracture toughness of alloy X-750 has been investigated. The material has been irradiated at a target temperature of $288^{\circ} \mathrm{C}$ in the Advanced Test Reactor at Idaho National Laboratory to a fluence of approximately $1.93 \times 10^{20} \mathrm{n} / \mathrm{cm}^{2}(\mathrm{E}>1 \mathrm{MeV})$. Stress corrosion cracking crack growth rates were determined in both unirradiated and irradiated materials in normal water chemistry and hydrogen water chemistry environments. Although the effect of irradiation on tensile properties and fracture toughness was observed, there was no significant effect of irradiation observed on the propagation rate of stress corrosion cracks.
\end{abstract}

\section{INTRODUCTION}

Nickel based alloy X-750 is used in commercial boiling water reactors (BWR) in locations where it is exposed to varying levels of neutron irradiation. To address the knowledge gaps associated with the effect of irradiation of X-750 on stress corrosion cracking susceptibility and fracture toughness, a Nuclear Science User Facilities (NSUF) project was designed in collaboration with the Electric Power Research Institute (EPRI) to irradiate and test X-750. This pilot project is being conducted in three phases. Phase I included the fabrication of specimens and established the baseline fracture toughness and crack growth rates (CGR) of unirradiated material. Phase II involved the design and fabrication of specimen holders and performance of a safety analysis of the experiment in preparation for irradiation of tensile and compact tension specimens utilizing the Loop 2A that is located in the Advanced Test Reactor (ATR) center flux trap. In the current and final Phase III, post irradiation examination including tensile testing, crack growth rate (CGR) testing, fracture toughness testing, and TEM analyses is being conducted. 


\section{EXPERIMENTAL PROCEDURES}

\section{A. Material and irradiation conditions}

Several sections of Inconel ${ }^{1}$ alloy X-750 were provided to Idaho National Laboratory (INL) by General Electric Global Research Center (GE-GRC). These sections were removed by GE-GRC from a spare upper support bracket that was purchased from Southern Co. by EPRI. The material was delivered in the High Temperature Heat-Treatment (HTH) condition which consists of a $35 \%$ minimum reduction hot roll; solution anneal at $1107^{\circ} \mathrm{C}$ for 1 hour and rapid cool; aging at $704{ }^{\circ} \mathrm{C}$ for 20 hours and air cool. The composition for this material is given in Table 1 and additional microstructural details may be found in [1].

Table 1: Composition of alloy X750 (wt.\%)

\begin{tabular}{|l|l|l|l|l|l|l|l|l|l|l|l|l|l|l|}
\hline $\mathrm{Al}$ & $\mathrm{C}$ & $\mathrm{Nb}+\mathrm{Ta}$ & $\mathrm{Co}$ & $\mathrm{Cr}$ & $\mathrm{Cu}$ & $\mathrm{Fe}$ & $\mathrm{Mg}$ & $\mathrm{Ni}$ & $\mathrm{P}$ & $\mathrm{S}$ & $\mathrm{Si}$ & $\mathrm{Ti}$ & $\mathrm{Ta}$ & Others \\
\hline 0.77 & 0.04 & 0.99 & 0.726 & 14.99 & 0.0151 & 7.8 & 0.197 & 70.8 & $<0.005$ & 0.002 & 0.253 & 2.42 & $<0.01$ & 0.97 \\
\hline
\end{tabular}

The irradiation program included three target fluences $\left(5.0 \times 10^{19} \mathrm{n} / \mathrm{cm}^{2}, 2.0 \times 10^{20} \mathrm{n} / \mathrm{cm}^{2}\right.$, and $1.0 \times 10^{21} \mathrm{n} / \mathrm{cm}^{2}, \mathrm{E}>1 \mathrm{MeV}$ ) to be performed in Loop $2 \mathrm{~A}$ of the ATR center flux trap at a target irradiation temperature of $288^{\circ} \mathrm{C}$. The control of the irradiation temperature was not optimum during the experiment which led to several of the specimens reaching a temperature of $340^{\circ} \mathrm{C}$ in the first irradiation cycle and most specimens achieving a temperature of $\sim 265^{\circ} \mathrm{C}$ during the second irradiation cycle. The data presented in this paper only includes the specimens irradiated to the intermediate fluence (actual measured fluence was $1.93 \times 10^{20} \mathrm{n} / \mathrm{cm}^{2}$ ) which corresponds to a dose of 0.28 dpa using the correlation of $6.84 \times 10^{20} \mathrm{n} / \mathrm{cm}^{2}(\mathrm{E}>1 \mathrm{MeV})$ per dpa.

\section{B. Fracture Toughness and IASCC Testing}

Fracture toughness and IASCC testing were performed on $0.4 \mathrm{~T} \mathrm{CT}$ specimen with side grooves along the crack path. The stress corrosion cracking tests were performed in controlled water chemistry testing loops. The water was continuously refreshed with a flow rate of approximately $200 \mathrm{ml} / \mathrm{min}$ for a 4-liter autoclave and the water chemistry was continuously monitored and controlled. Dissolved gas concentration was controlled by applying an overpressure of mixed gas at room temperature before the water flowed to the high pressure high temperature part of the loop. The ion content was controlled by flowing water through an ion exchange column to remove corrosion products and by adding a controlled amount of sulfate $\left(\mathrm{SO}_{4}\right)$ when desired for crack growth rate control. Typically the tests were performed in normal water chemistry (NWC) with $2 \mathrm{ppm}$ dissolved oxygen in pure water and hydrogen water chemistry (HWC) with approximately 63 ppb dissolved hydrogen in pure water. In order to

${ }^{1}$ Inconel is a registered trademark of Special Metals Incorporated. 
facilitate intergranular cracking engagement and to remain consistent with the methodology employed by Andresen [1] previously with this material, sulfate addition (up to $30 \mathrm{ppb}$ ) was occasionally used. Test control and monitoring was accomplished using the AT5 software $[2,3]$ provided by the GE Global Research Center (GE-GRC). This software utilizes reversing, direct current potential drop (DCPD) to measure crack growth during CGR and J-R tests.

The tests were generally performed in four steps: (1) initiation of a fatigue crack in environment for irradiated specimens or in air for unirradiated specimens, (2) transition from fatigue to stress corrosion cracking in the environment, (3) stress corrosion cracking in the various environments and conditions of interest, and (4) post-test fatigue.

Typically, a crack was initiated and extended by fatigue from the machined notch by a three step fatigue program. After several days in the environment to assure stabilization of the corrosion potential, crack extension was continued in the environment with a frequency that decreased from 0.1 to $0.001 \mathrm{~Hz}$ followed by introduction of a hold time of 9000s at $\mathrm{K}_{\max }$ to transition the transgranular fatigue crack to an intergranular stress corrosion crack. The experiment was then performed at a constant $\mathrm{K}$. The series of steps followed to prepare a specimen for a SCC test under a constant $\mathrm{K}$ applied of $25 \mathrm{ksi}$ in is presented in Table 2.

Table 2: Example of crack conditioning steps for a constant $K=25 \mathrm{ksi} \backslash \mathrm{in}$ experiment

\begin{tabular}{|c|c|c|c|c|}
\hline Step \# & $\begin{array}{c}\mathrm{K}_{\max } \\
(\mathrm{ksi} \sqrt{ } \mathrm{in})\end{array}$ & $\begin{array}{c}\text { Ratio } \\
\mathrm{K}_{\min } / \mathrm{K}_{\max }\end{array}$ & Frequency (Hz) & $\begin{array}{c}\text { Holding } \\
\text { time (s) }\end{array}$ \\
\hline 1 & 23 & 0.2 & 1 & 0 \\
\hline 2 & 24 & 0.4 & 1 & 0 \\
\hline 3 & 25 & 0.6 & 1 & 0 \\
\hline 4 & 25 & 0.6 & 0.1 & 0 \\
\hline 5 & 25 & 0.6 & 0.01 & 0 \\
\hline 6 & 25 & 0.6 & 0.001 & 0 \\
\hline 7 & 25 & 0.6 & 0.001 & 9000 \\
\hline $\mathbf{8}$ & Constant 25 & $\mathbf{1}$ & & \\
\hline
\end{tabular}

The targeted constant K was maintained while the specimen was held in NWC and HWC. At the end of the test, the specimen was ruptured by fatigue and the fracture surface was analysed using optical and scanning electron microscopy. From the fracture surface, the percentage difference (error) between the propagated crack as determined with the DCPD technique and the actual measured crack propagation was determined as (actual-DCPD)/actual*100. This post-test computed error was used as a basis to compensate for the commonly observed discrepancy between DCPD measured crack lengths and the actual physically measured crack length. Crack growth rates were corrected using this calculated difference.

Fracture toughness tests for unirradiated specimens were performed using a dual zone high 
temperature box furnace for temperature control. The crack tip temperature was monitored during testing for all specimens by welding a type $\mathrm{K}$ thermocouple spanning the crack path and approximately $5 \mathrm{~mm}$ ahead of the notch tip as well as an additional type $\mathrm{K}$ thermocouple welded to the top edge of the specimen to ensure negligible temperature gradient within the specimen. All tests were performed according to American Society for Testing of Materials (ASTM) Standard E1820-09 "Standard Test Method for Measurement of Fracture Toughness" [4]. Fracture toughness tests with irradiated specimens were performed using the same system used for IASCC testing but in air. Specimen temperature was controlled by controlling the temperature of the autoclave with a thermocouple located near, but not attached to, the specimen. Elongation and strain rate were determined by crosshead displacement and crack growth was measured by DCPD technique.

\section{C. Tensile Testing}

Tensile properties of the unirradiated specimens were performed according to the ASTM Standard E8 "Standard Test Methods for Tension Testing of Metallic Materials" [5]. The specimens were dogbone specimens with a cylindrical gage section. The nominal gage cross section was $0.25 \mathrm{inch}$ and the gage length was $1 \mathrm{inch}$. The specimens were machined with their tensile axis along the longitudinal (L), or rolling direction, to coincide with the L-T orientation of the CT specimens used in fracture testing and SCC testing. For characterization of tensile properties of the irradiated specimens, crosshead displacement was the method used for measuring elongation during remote tensile testing.

\section{RESULTS AND DISCUSSION}

\section{Tensile tests}

The results of the tensile tests performed at $288^{\circ} \mathrm{C}$ are shown in Figure 1 and summarized in Table 3. Testing performed with unirradiated specimens provided very similar results. Two tensile tests were performed and results were identical to those obtained by M. Morra [6]. Only one representative data set is shown in this table. The average $0.2 \%$ offset yield strength $\left(\sigma_{\mathrm{y}}\right)$ for alloy X-750 was $713.5 \mathrm{MPa}$, the average tensile strength $\left(\sigma_{\mathrm{ult}}\right)$ was $1079 \mathrm{MPa}$, and the average strain to failure $\left(\varepsilon_{\mathrm{f}}\right)$ was $31.1 \%$. After irradiation, irradiation hardening and reduction of strain to failure were observed. The $0.2 \%$ offset yield strength increased to $972 \mathrm{MPa}$ and strain to failure decrease to $13 \%$. However, there was a noticeable difference between the two tests performed. Similarly, differences were observed in the hardness measurements taken across the specimen (cross sections of the tensile specimens' head) as shown in Figure 2. Although the hardness is similar in the center of the specimens, the surface hardness of specimen EP1-L3 is about 470HV while it is only $390 \mathrm{HV}$ on specimen EP1-L4. 


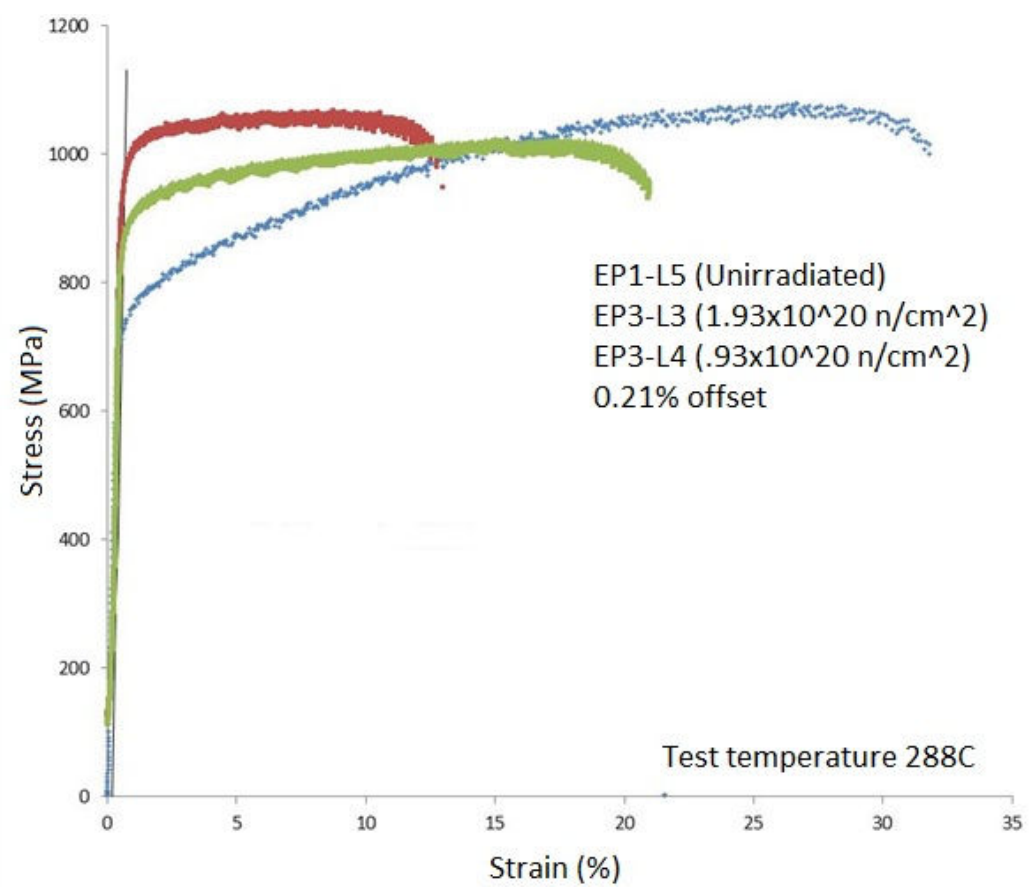

Figure 1. Strain-stress curves obtained at $288^{\circ} \mathrm{C}$ with unirradiated and irradiated $\mathrm{X} 750$

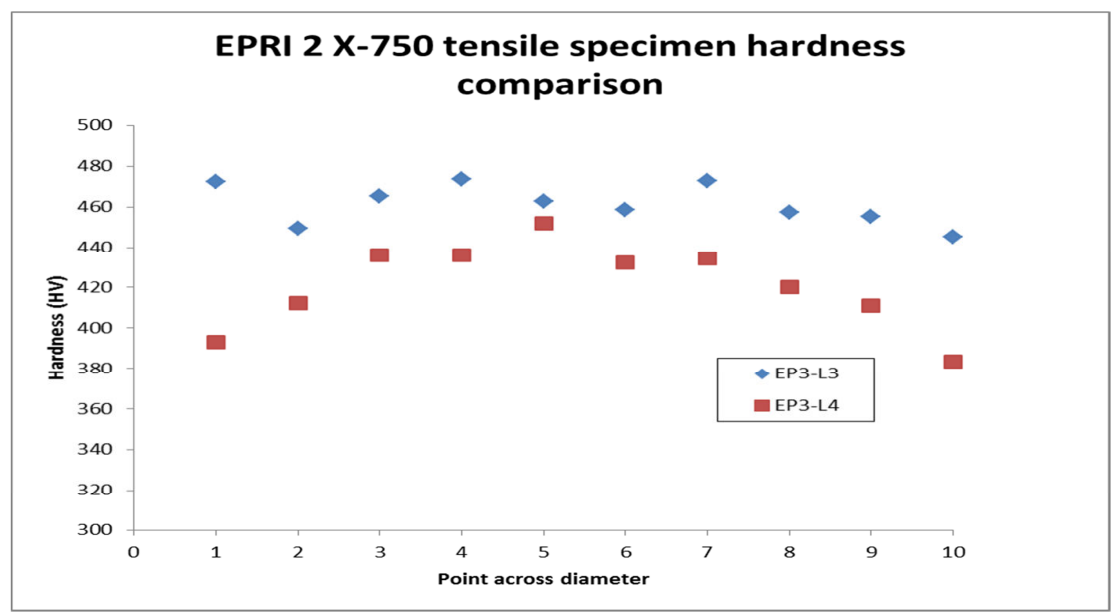

Figure 2. Hardness measurements taken across the cross section of the tested specimens.

Table 3. Tensile properties at $288^{\circ} \mathrm{C}$ as a function of dose

\begin{tabular}{|l|c|c|c|c|}
\hline Specimen ID & Dose (dpa) & $0.2 \%$ YS (Mpa) & UTS (Mpa) & Elongation (\%) \\
\hline EP1-L5 & 0 & 715 & 1082 & 30 \\
\hline EP1-L3 & 0.28 & 962 & 1067 & 13 \\
\hline EP1-L4 & 0.28 & 877 & 1023 & 21 \\
\hline
\end{tabular}




\section{Fracture toughness}

For all tests performed with unirradiated specimens, $\mathrm{J}_{\mathrm{Q}}$ was qualified as $\mathrm{J}_{\mathrm{IC}}$, a geometry independent fracture toughness because all specimens met the requirements for this qualification per ATSM E1820-09. The test performed with irradiated specimens did not meet the standard therefore $\mathrm{J}_{\mathrm{Q}}$ is reported because the curvature of the final crack front exceeded the allowable deviation of the crack length value. The representative fracture toughness results for irradiated and unirradiated specimens are summarized in Table 3. Fracture toughness $\left(\mathrm{J}_{\mathrm{IC}}, \mathrm{J}_{\mathrm{Q}}\right)$ generally decreased and tearing modulus which is an indication of residual toughness also decreased. Figure 3 shows an overlay plot of the full J-R curves for unirradiated and irradiated testing.

Table 2. Fracture toughness results at $288^{\circ} \mathrm{C}$

\begin{tabular}{|c|c|c|}
\hline Dose (dpa) & $\mathbf{J}_{\mathbf{I C}}$ or $\mathbf{J}_{\mathbf{Q}}\left(\mathrm{kJ} / \mathrm{m}^{2}\right)$ & Tearing modulus \\
\hline 0 & 163.5 & 78 \\
\hline 0 & 160.8 & 70 \\
\hline 0 & 132.6 & 81 \\
\hline 0.28 & 99.39 & 55 \\
\hline 0.28 & 121 & 60 \\
\hline
\end{tabular}

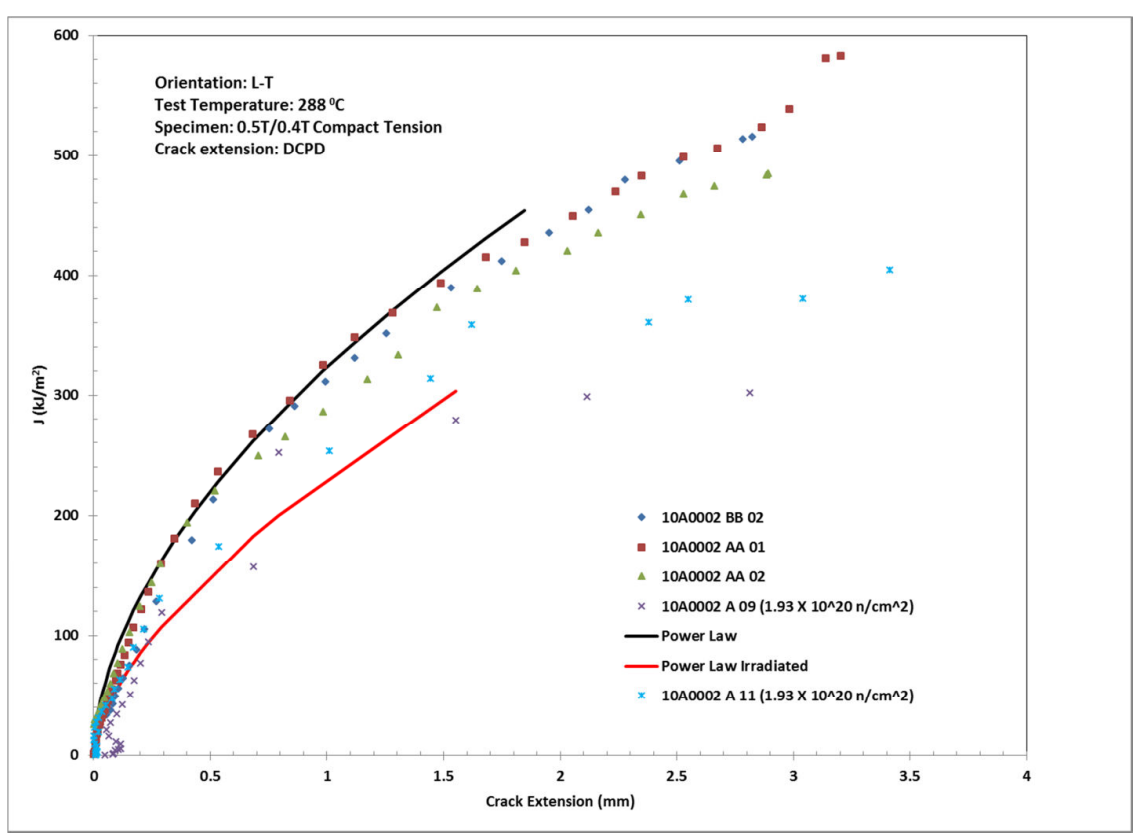

Figure 3: Overlay plot showing effect of irradiation to 0.28 dpa on X-750 


\section{SCC and IASCC testing}

Unirradiated X-750 exhibited high crack growth rates that were consistent with the crack growth rates determined elsewhere (1). Figure 4 shows an example of the response of a specimen tested under a constant applied $\mathrm{K}=27.5 \mathrm{Mpa} \sqrt{\mathrm{m}}(25 \mathrm{ksi} \sqrt{ } \mathrm{in})$ in BWR water containing $10 \mathrm{ppb}$ sulfate both in NWC and HWC. The CGR $\left(1.5 \times 10^{-6} \mathrm{~mm} / \mathrm{s}\right)$ measured in NWC is reduced to $5.3 \times 10^{-8} \mathrm{~mm} / \mathrm{s}$ when the environment is changed to HWC. This behavior has been reproducible over the various test performed within this project. The various CGRs measured in NWC range from $8.8 \times 10^{-7} \mathrm{~mm} / \mathrm{s}$ to $1.8 \times 10^{-6} \mathrm{~mm} / \mathrm{s}$ and from $1.3 \times 10^{-8} \mathrm{~mm} / \mathrm{s}$ to $1.3 \times 10^{-7} \mathrm{~mm} / \mathrm{s}$ in HWC, respectively. On average the change in crack growth rate via reduction of ECP is about a factor of 22.

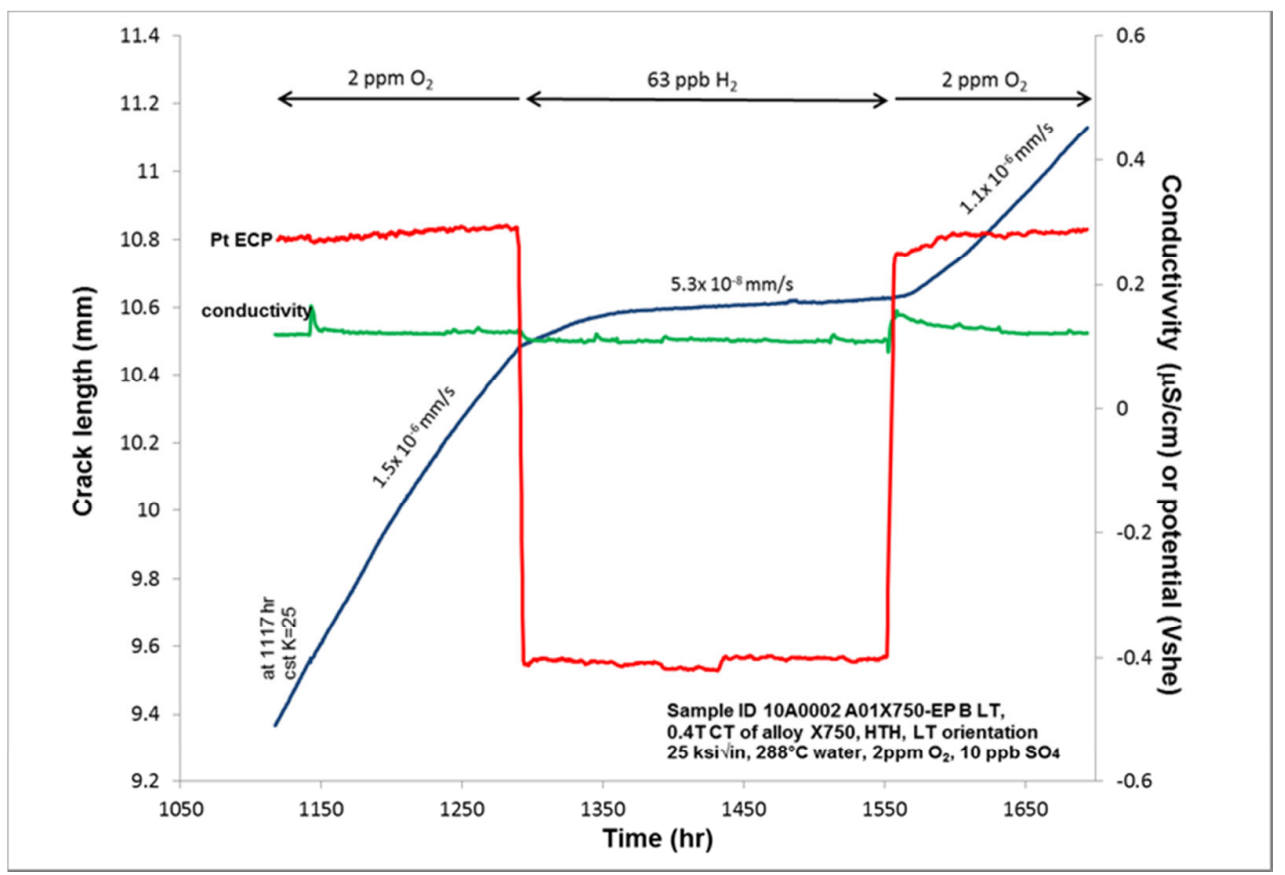

Figure 4. Crack length versus time obtained with unirradiated X-750

Irradiated specimens exhibited similar crack growth rates to the unirradiated materials. Under a constant applied $\mathrm{K}$ of $27.5 \mathrm{Mpa} \sqrt{\mathrm{m}}(25 \mathrm{ksi} \sqrt{ } \mathrm{in})$, crack growth rates of $1.6 \times 10^{-6} \mathrm{~mm} / \mathrm{s}$ were measured in NWC. The crack growth rate decreased sharply to $5.9 \times 10^{-8} \mathrm{~mm} / \mathrm{s}$ when testing was performed in HWC. The ECP benefit obtained was observed under various applied constant $\mathrm{K}$ (Figure 5).

The comparison of all crack growth rates generated in this study confirms that there is no significant change in CGR after irradiation to $1.9 \times 10^{20} \mathrm{n} / \mathrm{cm}^{2}$ (Figure 6) and the K dependency remains the similar (Figure 7). 

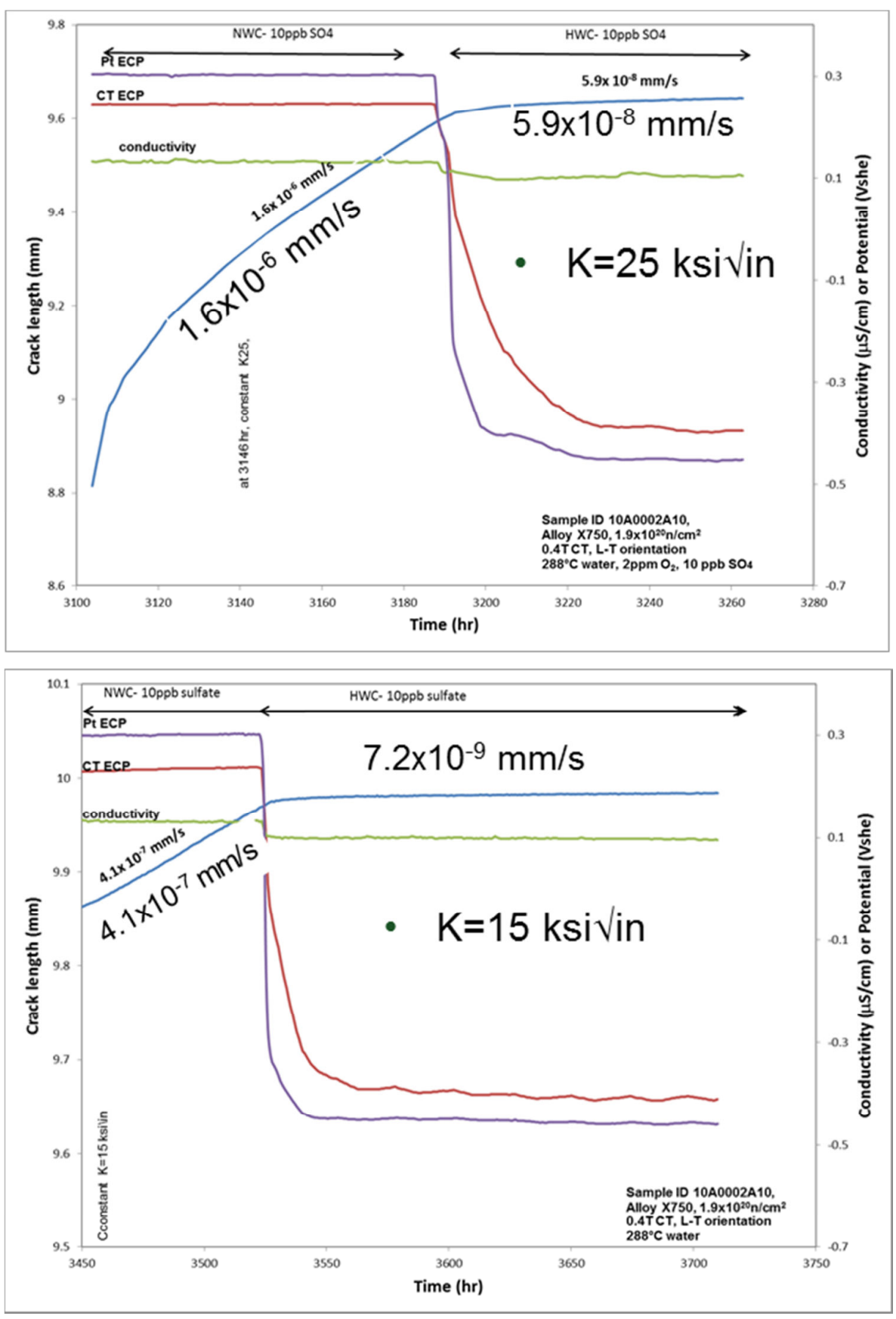

Figure 5. Crack length versus time for irradiated X-750 


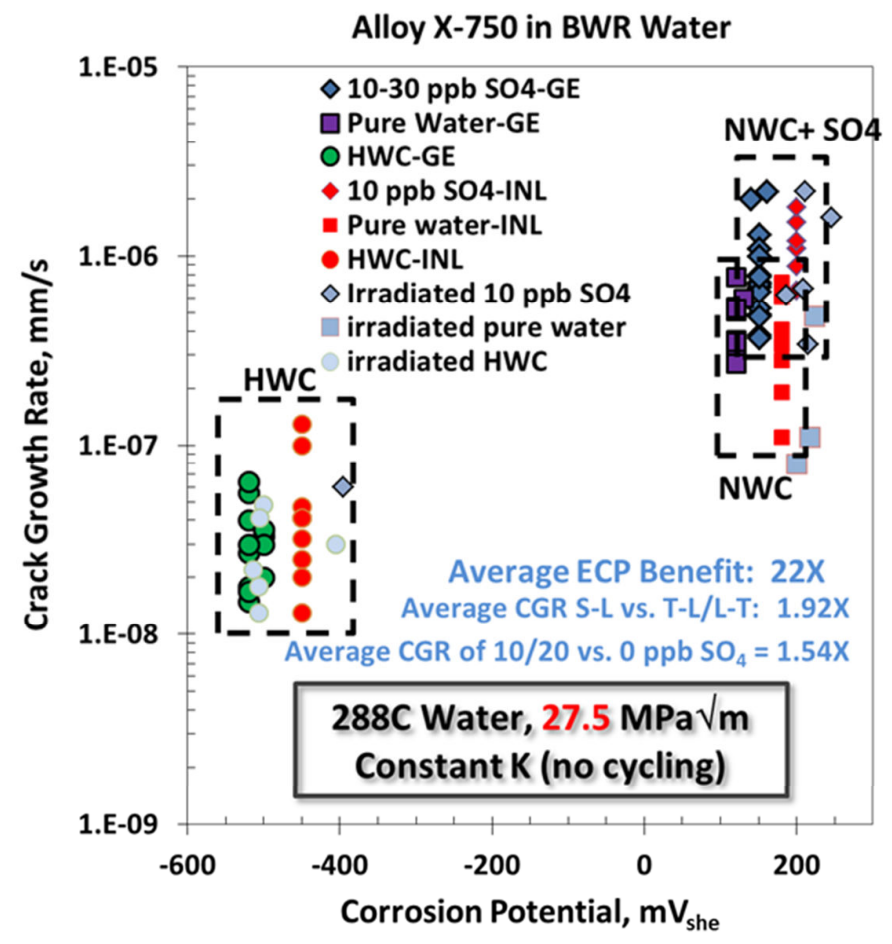

Figure 6. Effect of corrosion potential on crack growth rate, GE data from (1).

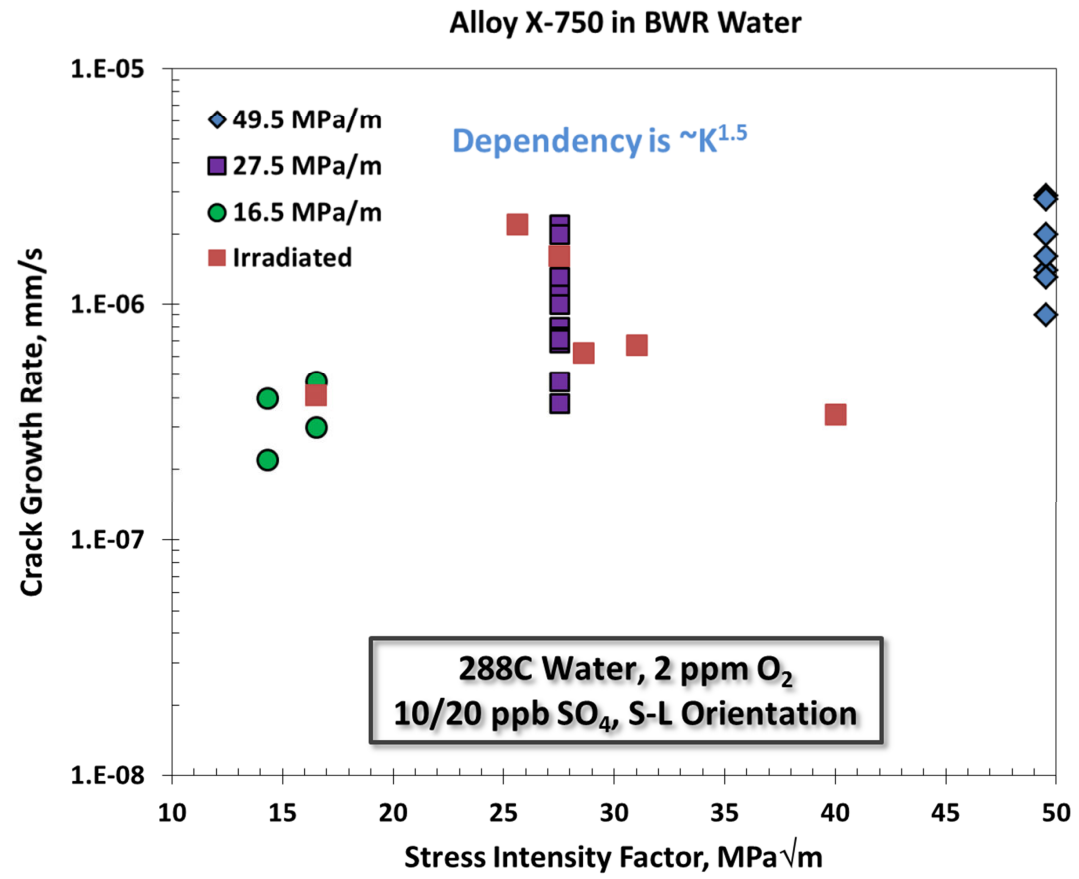

Figure 7. K dependency for unirradiated and irradiated X-750 tested in BWR NWC water 


\section{CONCLUSIONS}

$\mathrm{X}-750$ specimens irradiated to the fluence of $1.93 \times 10^{20} \mathrm{n} / \mathrm{cm}^{2}$ did not exhibit an increased CGR compared to unirradiated X-750 (HTH) tested in both NWC and HWC conditions. The effectiveness of the HWC mitigation was retained after irradiation as the influence of corrosion potential remained unchanged. The $\mathrm{K}$ dependency did not appear affected by irradiation. However, irradiation hardening was observed along with a nominal reduction of fracture toughness to approximately $72 \%$ (average) of the unirradiated values.

\section{ACKNOWLEDGMENTS}

This work was supported under a Cooperative Research and Development Agreement between the Idaho National Laboratory (under the Nuclear Science User Facilities) and the Electric Power Research Institute.

\section{REFERENCES}

1- P. L. Andresen, J. Flores-Preciado, M. Morra and R. Carter, "Microstructure and SCC of Alloy X-750", $15^{\text {th }}$ International Conference on Environmental Degradation of Materials in Nuclear Power Systems-Water reactors, 2011

2- P.L. Andresen, "The Effects of Aqueous Impurities on Intergranular Stress Corrosion Cracking of Sensitized Type 304 Stainless Steel," Final Report NP3384 Contract T115-3, EPRI, 1983.

3- P.L. Andresen and C.L. Briant, "Environmentally Assisted Cracking of Types 304L/316L/316NG Stainless Steel in $288^{\circ}$ C Water," Corrosion, Vol. 45, p. 448-463, 1989.

4- Standard test method for measurement of fracture toughness. ASTM E 1820-09. West Conshohocken, PA : ASTM International, 2009

5- Standard Test Methods for Tension Testing of Metallic Materials. ASTM E 8-04. West Conshohocken, PA : ASTM International, 2004.

6- BWRVIP-240: BWR Vessels and Internals Project, Metallurgical Analyses and Macro and Microstructural Mapping of Alloy X-750 and Alloy XM-19 Plates. Palo Alto, CA : EPRI, 2010. 1021003. 